\title{
Thermal and Optical Properties of Porous Silicon
}

\author{
A. Ferreira da Silva ${ }^{\mathrm{a}}$, T. Souza da Silva ${ }^{\mathrm{a}}$, O. Nakamura ${ }^{\mathrm{a}}$, \\ M.M.F. d'Aguiar Neto ${ }^{\mathrm{a}}$, I.Pepe ${ }^{\mathrm{a}}$, L. S. Roman ${ }^{\mathrm{b}}$, E. Veje $^{\mathrm{c}}$ \\ ${ }^{\mathrm{a}}$ Instituto de Física, Universidade Federal da Bahia, \\ Campus Universitário de Ondina, 40210-340 Salvador - Ba, Brasil \\ bepartamento de Física, Universidade Federal do Paraná, \\ C.P. 19044, 81531-990 Curitiba - Pr, Brazil \\ ${ }^{\mathrm{c}}$ Department of Electric Power Engineering, Technical University of Denmark, \\ Building 325, DK-2800 Lyngby, Denmark
}

Received: October 19, 2000; Revised: January 8, 2001

\begin{abstract}
Thermal diffusivity and optical absorption have been investigated for porous silicon, at room temperature, using photoacoustic spectroscopy. The experimental results obtained conform well with the existing studies recently published. The value obtained for thermal diffusivity is $0.045 \pm 0.002 \mathrm{~cm}^{2} / \mathrm{s}$. The absorption onsets show energy structures, differing from the ordinary semiconductor of bulk type. PACS 51.20.Td; 74.25.Fy; 73.20.Dy; 78.20.Wc; 81.40.Tv
\end{abstract}

Keywords: thermal properties, optical properties, photoacoustic spectroscopy, porous silicon

\section{Introduction}

Owing to the wide-ranging of possible technological applications in opto-electronic devices ${ }^{1-27}$ and biocompatible materials as well ${ }^{28-33}$, the interest in characterizing porous silicon (PS) has recently increased very much. Porous silicon has been studied intensively since the discovery by $\mathrm{Canham}^{1}$, that even at room temperature PS can emit very bright photoluminescence (PL), in great contrast to crystalline silicon (c-Si). Usually, the PS samples are produced by anodic etching of c-Si wafers in hydrofluoric (HF) solution.

A large amount of investigations is devoted to the PL and absorption measurements of $\mathrm{PS}^{1-6,8}$, but so far there has been a few reports on its thermal properties ${ }^{7,17,18,34,35}$. In this work we have devoted our attention to obtain, by applying the photoacoustic spectroscopy (PAS), the optical absorption and the thermal diffusivity, which is, as other optical properties, an important physical parameter to be considered in device modeling, specially for power dissipation. The PAS spectra are obtained directly from the heat generated in a sample, due to nonradiative absorption processes $^{36,37}$. The fact that the PA signal depends on how the heat diffuses through the sample enable us to measure its thermal diffusivity ${ }^{7,17,18,38}$. The experimental PA setups, consisting of a periodically exciting light source, a photoa- coustic cell containing the sample and a microphone are described in details in Refs. 37 and 38 for optical absorption and thermal diffusivity respectively.

\section{Experimental}

The samples were produced by etching p-type c-Si wafers of crystal orientation (100) and resistivity $1-30 \Omega \mathrm{cm}$ eletrochemycally in 40\% HF: ethanol 1:1. The electrolytic cell as well as the etching procedure are described in Ref. 5. Current densities from $5 \mathrm{~mA} / \mathrm{cm}^{2}$ to $25 \mathrm{~mA} / \mathrm{cm}^{2}$ were used and in each case, the current density was always kept constant during etching. Etching times were from 60 to $90 \mathrm{~min}$, so that all samples consisted of a fairly thick layer of PS. Scanning force microscopy (SFM) investigation revealed a typical thickness of around $30 \mu \mathrm{m}$.

The SFM measurements were performed using a Digital Instrument Nanoscope III running in tapping mode. In this imaging mode, the SFM tip-cantileve oscillates sinusoidally at high frequencies $(300 \mathrm{kHz})$ with amplitude $10-100$ $\mathrm{nm}$, so that the tip contacted the surface once during each period. The data were taken in ambient air at room temperature. The samples were stored in air for a long time $(>>1$ month), so that surface oxidation had equilibrated. This implies that the surface structure is fairly reproducibly and does not change in time. Scans were made over areas from

e-mail: ferreira@ fis.ufba.br 
$500 \times 500 \mathrm{~nm}$ to $20 \times 20 \mu \mathrm{m}$ with a resolution of $512 \times 512$ pixels and the scan rate of $1-2 \mathrm{~Hz}$.

\section{Results and Discussion}

Figure 1 shows a typical SFM image of p-type PS sample produced with 60 min etching time. In Fig. 2 we show the PA spectrum of the same sample used for Fig. 1. Several spectral features are seen, revealing the complex band system originated from the surface roughness as shown in Fig. 1. The PA energies are respectively $1.603 \pm 0.048,1.668 \pm 0.050,1.751 \pm 0.052,1.882 \pm 0.056$, $2.025 \pm 0.086$ and $2.143 \pm 0.064 \mathrm{eV}$. Such structures have

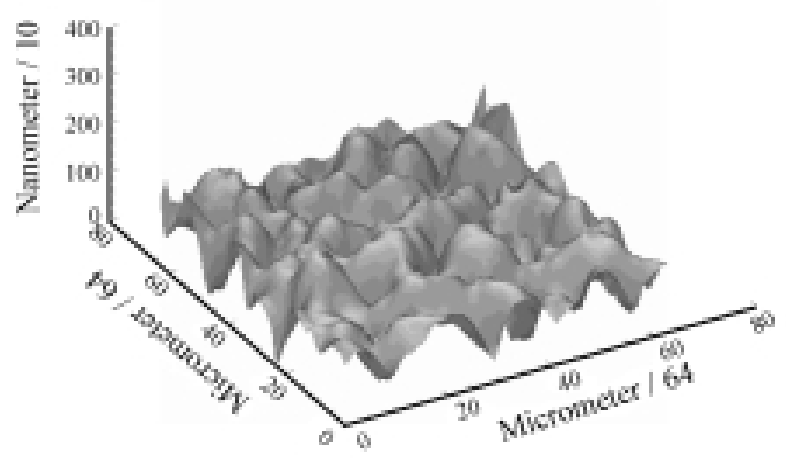

Figure 1. The SFM image of the PS sample. The axes units have been chosen in order to provide a better image presentation. Details in the text.

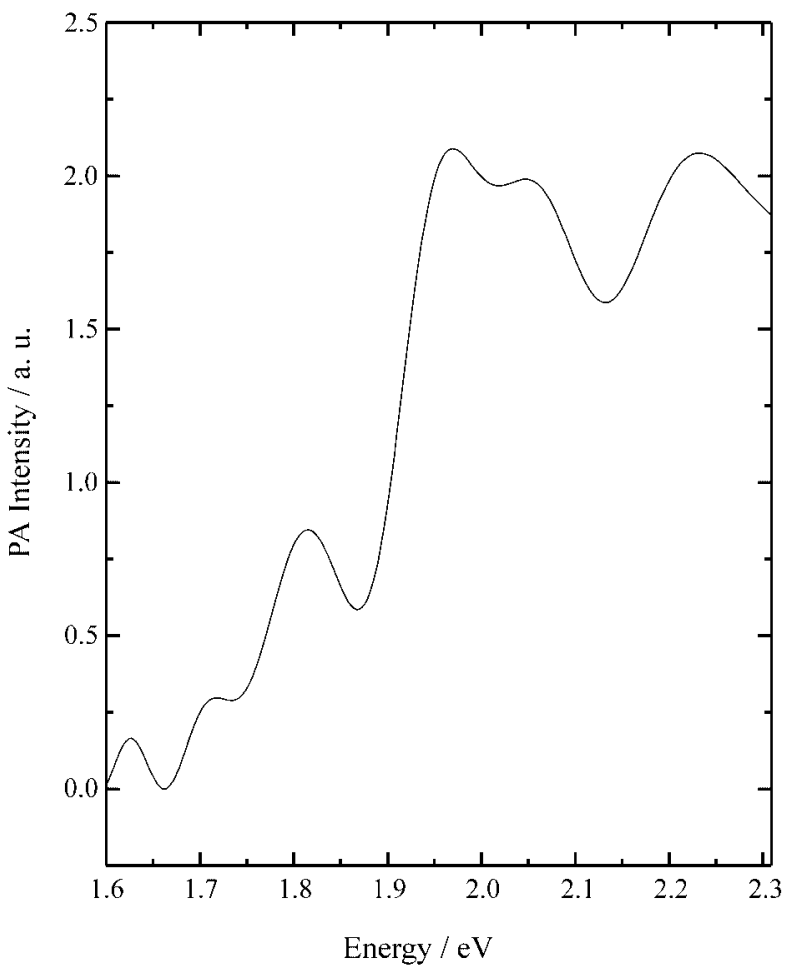

Figure 2. A typical PAS spectrum from a PS sample. The PAS signal is plotted versus the photon energy of the illuminating light. Same PS sample used for Fig. 1. recently been confirmed by PL, photoluminescense excitation (PLE) and photocurrent measurements ${ }^{21,26}$.

To measure thermal diffusivity, the acoustic signal produced in the gas cavity by the sample is detected by a Sunheiser condensed microphone and analyzed in respect to the modulator reference by a lock-in amplifier ${ }^{38}$. For the transmission arrangement, corresponding to the rear-side excitation of a thermally thick sample, the thermoacoustic phase contribution is given by the equation ${ }^{38}$.

$$
\Phi=\Phi_{0}+\arctan \left\{\mathrm{L}_{\mathrm{s}}\left[\left(\pi / \alpha_{\mathrm{s}}\right) f\right]-1\right\}^{-1},
$$

where $\Phi_{0}$ is the initial phase, $\alpha_{s}$ is the thermal diffusivity, $\mathrm{L}_{\mathrm{s}}$ is the sample thickness $\left(\mathrm{L}_{\mathrm{s}}=530 \mu \mathrm{m}\right)$, and $f$ is the chopping frequency. These parameters are determined by a numerical least-squares fitting procedure. In Fig. 3 we show the rear-PA intensity as a function of the chopping frequency $f$ for the PS sample. It is shown that the PA signal intensity $S$ is proportional to $f^{\lambda}$, for our best set of measurements $\lambda=-0.92$. Figure 4 shows the chopping frequency dependence of rear-signal phase. The solid curve represents the best fit of the data to Eq. (1). The value obtained for the thermal diffusivity, at room temperature is $\alpha_{\mathrm{s}}=0.045 \pm 0.002 \mathrm{~cm}^{2} / \mathrm{s}$. This value may be compared to $\alpha_{\mathrm{s}}=0.047 \mathrm{~cm}^{2} / \mathrm{s}$ and $\alpha_{\mathrm{s}}=0.053 \mathrm{~cm}^{2} / \mathrm{s}$ recently found ${ }^{7,18}$ by Cruz-Orea et al. ${ }^{7}$ and Calderón et al. ${ }^{18}$, respectively, with open photoacoustic cell method. It is worthwhile to point out that there are some discrepancies between thermal conductivity values in the literature ${ }^{7,17,18,25}$. Like the thermal diffusivity, the thermal conductivity $k$ is another important parameter to manufacturing devices. The

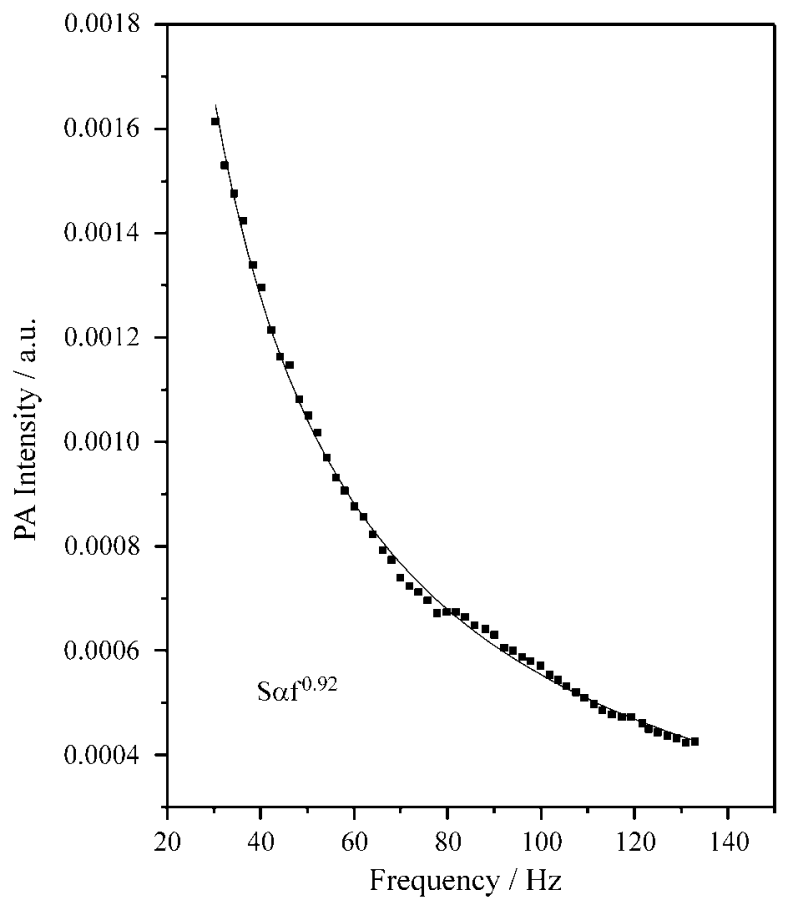

Figure 3. PAS intensity $v s$. chopper frequency for PS sample. 
Table 1. Measured values of thermal diffusivity $\alpha_{\mathrm{s}}$ and thermal conductivity $k$ for porous silicon. In the fourth column $k_{\text {mean }}$ stands for the computed average. The corresponding average of $k$ for p-type samples is $\alpha_{\mathrm{s}}=0.032 \pm 0.018 \mathrm{~W} / \mathrm{cmK}$.

\begin{tabular}{lcccc}
\hline Author & $\alpha_{\mathrm{s}}\left(\mathrm{cm}^{2} / \mathrm{s}\right)$ & $k(\mathrm{~W} / \mathrm{cmK})$ & $k_{\text {mean }}(\mathrm{W} / \mathrm{cmK}) \mathrm{p}$-type & Sample type \\
\hline Present work & $0.045 \pm 0.002$ & 0.075 & $0.053 \pm 0.022$ & $\mathrm{p}$ \\
& & 0.031 & $\mathrm{p}$ & $\mathrm{n}$ \\
Cruz-Orea $^{7}$ & 0.047 & 0.0074 & - & $\mathrm{n}$ \\
Caldereón $^{18}$ & $0.053 \pm 0.0035$ & 0.130 & $0.032 \pm 0.013$ & $\mathrm{p}$ \\
Amato $^{17}$ & & 0.025 & & $\mathrm{p}$ \\
& & 0.039 & $\mathrm{n}$ & $\mathrm{p}$ \\
Shinoda $^{25}$ & & 0.312 & 0.010 & \\
\hline
\end{tabular}

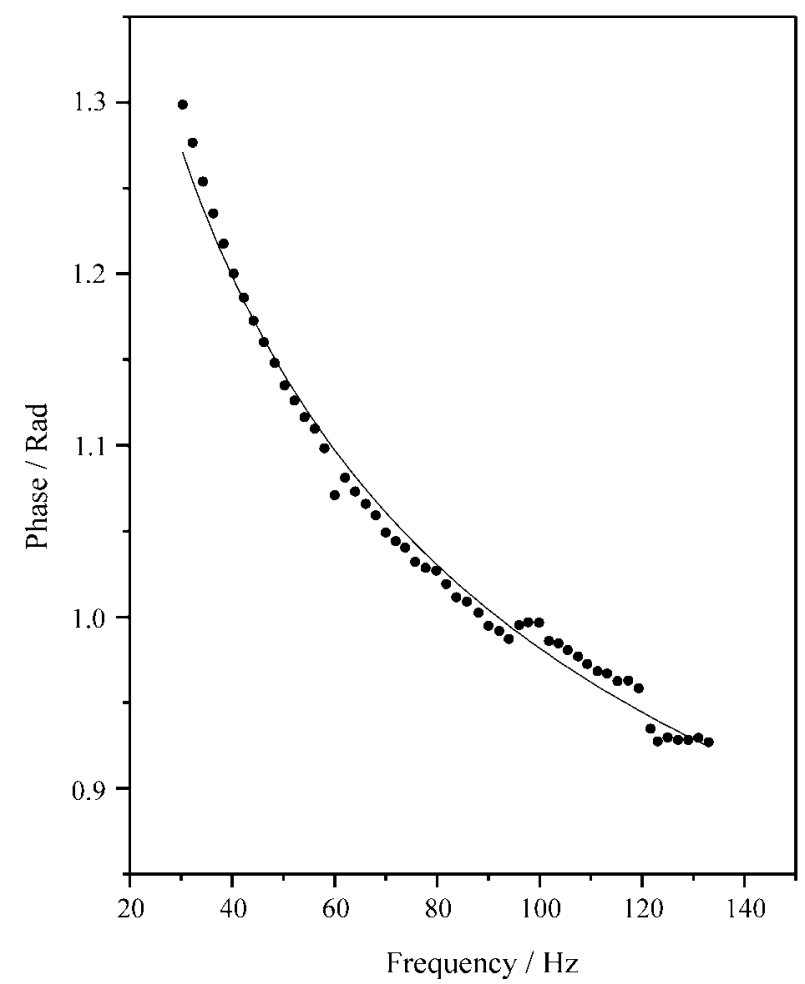

Figure 4. Chopper frequency dependence of the rear signal. The solid curve represents the best fit of the data to Eq. (1). The best value for the thermal diffusivity is $\alpha_{\mathrm{S}}=0.045 \pm 0.002 \mathrm{~cm}^{2} / \mathrm{s}$.

measurement of $\alpha_{\mathrm{s}}$ allows us to obtain $k$, once the density $\rho$ and the specific heat $\mathrm{C}_{\mathrm{v}}$ are know. We determine $k$ by the relation $k=\alpha_{\mathrm{s}} \rho \mathrm{C}_{\mathrm{v}}$. Cruz-Orea $^{7}$ with a spark-process PS found $k=0.0074 \mathrm{w} / \mathrm{cmK}$ and $\alpha_{\mathrm{s}}=0.047 \mathrm{~cm}^{2} / \mathrm{s}$, Calderón et al., with the usual eletrochemical etching process found $k=0.130 \pm 0.006 \mathrm{~W} / \mathrm{cmK}$ and $\alpha_{\mathrm{s}}=0.053 \pm 0.0035 \mathrm{~cm}^{2} / \mathrm{s}$ respectively. They have used a n-type PS. Amato et al. ${ }^{17}$, found, for p-type PS the values $k=0.025 \mathrm{~W} / \mathrm{cmK}$ and $k=0.039 \mathrm{~W} / \mathrm{cmK}$ respectively for two different samples, while a value of $k=0.312 \mathrm{~W} / \mathrm{cmK}$ for a n-type PS. Shinoda et $a l .{ }^{25}$, with a thermally induced ultrasonic technique found $k=0.01 \mathrm{~W} / \mathrm{cmK}$. We may mention that Amato et $a l .{ }^{17}$, have used forheat capacity a value equal to that of $\mathrm{c}-\mathrm{Si}$. Using the heat capacity of c-Si, $\mathrm{C}_{\mathrm{v}}=1.67 \mathrm{~J} / \mathrm{cm}^{3} \mathrm{~K}$ and of PS from Shinoda et al. ${ }^{25} \cdot \mathrm{C}_{\mathrm{v}}=0.7 \mathrm{~J} / \mathrm{cm}^{3} \mathrm{~K}$ we found $k=0.075$ $\mathrm{W} / \mathrm{cmK}$ and $k=0.031 \mathrm{~W} / \mathrm{cmK}$ respectively. The results above confirm the good possibility for thermal insulation given by PS layers in contrast to $\mathrm{c}-\mathrm{Si}$, which has higher thermal properties, i.e., $\alpha_{\mathrm{s}}=0.9 \mathrm{~cm}^{2} / \mathrm{s}$ and $k=1.67 \mathrm{~W} / \mathrm{cmK}$.

In summary, we have obtained through the PAS technique, the complex structure of the band gap energies and the thermal diffusivity of porous silicon. Several absorption features were observed from the PAS spectrum. The positions of these features were found in a range of energy $1.603 \pm 0.048 \leq \mathrm{E} \leq 2.143 \pm 0.064 \mathrm{eV}$. The thermal diffusivity result is $0.045 \pm 0.002 \mathrm{~cm}^{2} / \mathrm{s}$, a value compared to other semiconductors of current technological importance ${ }^{38}$. The results conform well with the existing studies recently published, recognizing PS as a good material with potential to be used, for instance, thermal insulating layers and structures.

\section{Acknowledgments}

The authors would like to acknowledge the support of the Brazilian National Research Council, CNPq and SEPLANTEC/CADCT (Bahia). LSR acknowledges the financial support of the Göran Gustafsson foundation, and Thin Film Electronics AB, Sweden. EV is very grateful to support from the Danish Natural Science Research Council, the Carlsberg Foundation, Director Ib Henriksens Foundation, and the NOVO Nordic Foundation.

\section{References}

1. Canham, L.T. Appl. Phys. Lett., v. 57, p. 1046, 1990.

2.Canham, L.T.; Leong, W.Y.; Beale, M.I.J.; Cox, T.I.; Taylor, L. Appl. Phys. Lett., v. 61, p. 2563, 1992.

3.Lockwood, D.J.; Wang, A.; Bryskiewicz, B. Solid State Commun., v. 89, p. 587, 1994. 
4. Lockwood, D.J. Solid State Commun., v. 92, p. 101, 1994.

5. Andersen, O.K.; Veje, E. Phys. Rev., B53, 15643, 1996.

6. Miller, D.A.B. Nature, v. 384, p. 307, 1996.

7. Cruz-Orea, A.; Delgadillo, I.; Vargas, H.; GudinoMartinez, A.; Marin, E.; Vazquez-Lopez, C.; Calderon; A.; Alvarado-Gil, J.J. J. Appl. Phys., v. 79, p. 8951, 1996.

8. Pavesi, L. Microelectronics Journal, v. 27, p. 437, 1996.

9. Bjorklund, R.B.; Zangooie, S.; Arwin, H. Appl. Phys. Lett., 69, 3001, 1996; Adv. Matter, v. 9, p. 1067, 1997.

10. Chang, I.M.; Chen, Y.F. J. Appl. Phys., 82, 3514, 1997.

11. Collins, R.T.; Fauchet, P.M.; Tischler, M.A. Phys. Today, v. 50 n. 1, p. 24, 1997.

12. Canham, L.T., ed., Properties of Porous Silicon, EMIS Data Review Series n. 181 NSPEC, London chaps. 6, 7 and 10, 1997.

13. Cullis, A.G.; Canham, L.T.; Cacott, P.D. J. Appl. Phys., v. 82, p. 909, 1997.

14. Veje, E.; Ferreira da Silva, A.; Berggren, K-F.; Pepe, I.; Silva, A.V. Batista da. Pits and Pores: formation, properties and significance for advanced luminescence materials, Schmuki, P.; Lockwood, D.J.; Isaacs, H.; Bsiesy, A., eds., Proc. Electrochem. Soc., v. 97, n. 7, p. 242, 1997.

15. Romstad, F.C.; Veje, E. Phys. Rev., v. B55, p. 5220, 1997.

16. Gole, J.L.; Dudel, F.P.; Grantier; D.; Dixon, D.A. Phys. Rev., v. B56, p. 2137, 1997.

17. Amato, G.; Benedetto, G.; Boarino, L.; Brunetto, N.; Spagnolo, R. Opt. Eng., v. 36, p. 423, 1997.

18. Calderón, A.; Alvarado-Gil, J.J.; Gurevich, Y.G.; Cruz-Orea, A.; Delgadillo, I.; Vargas, H.; Miranda, L.C.M. Phys. Rev. Lett., v. 79, p. 5022, 1997.

19. Zangooie, S.; Jansson, R. ; Arwin, H. J. Vac. Sci. Technol., v. A16, p. 2901, 1998.

20. Pavesi, L.; Pauzarini, G.; Andreani, L.C. Phys. Rev., v. B58, p. 15794, 1998.

21. Frederiksen, J.T.; Melcher, P.G.; Veje, E. Phys. Rev., v. B58, p. 8020, 1998.

22. Gole, J.L.; Dixon, D.A. Phys. Rev., v. B57, p. 12002, 1998; J. Phys. Chem., v. B102, p. 1768, 1998.
23. Pavesi, L.; Mulloni, V. Proceedings of the International School of Physics Enrico Fermi, Course CXLI, Bisi, O.; Campisano, S.V.; Pavesi, L.; Priolo, F., eds., IOS Press, Amsterdam, p. 87, 1999.

24. Pavesi, L.; Chierchia, R.; Bellutti, P.; Lui, A.; Fuso, F.; Labardi, M.; Pardi, L.; Sbrana, F.; Allegrini, M.; Trusso, S.; Vasi, C.; Ventura, P.J.; Costa, L.C.; Carmo, M.C.; Bisi, O. J. Appl. Phys., v. 86, p. 6474, 1999.

25. Shinoda, H.; Nakajima, T.; Ueno, K.; Koshida, N. Nature, v. 400, p. 853, 1999.

26. Egeberg, R.C.; Veje, E.; Ferreira da Silva, A.; Pepe, I.; Alves, A. Santos. J. Porous Matter, v. 7, p. 173, 2000.

27. Ferreira da Silva, A.; Rosa, R.R.; Roman, L.S.; Veje, E.; Pepe, I. Solid State Commun., v. 113, p. 703, 2000.

28. Canham, L.T. Adv. Mater., v. 7, p. 1033, 1995.

29. Canham, L.T.; Reeves, C.L.; Leni, A.; Houlton, M.R.; Newey, J.P.; Simons, A.J.; Cox, T.I. Thin Sol. Fil., v. 297, p. 304, 1997.

30. Bayliss, S.C.; Buckberry, L.D.; Rousseau, C.; Harris, P. and Rousseau, Thin Sol. Fil., v. 297, p. 308, 1997.

31. Bayliss, S.C.; Harris, P.J.; L.D. Buckberry and Rousseau, J. Mater. Sci. Lett., v. 16, p. 737, 1997.

32. Buckberry, L.; Bayliss, S.C. Materials World, v. 7 n. 4, p. 213, 1999.

33. Bayliss, S.C.; Buckberry, L.D.; Fletcher; I.; Tobin, M.J. Sensors and Actuators A, v. 74, p. 139, 1999.

34. Benedetto, G.; Boarino, L.; Brunetto, N; Rossi, A.; Spagnolo, R.; Amato, G. Phil. Mag., v. B76, p. 383, 1997

35. Amato, G.; Angelucci, R.; Benedetto, G.; Boarino, L.; Dori, L.; Maccagnani, P.; Brunetto, N.; Rossi, A.M.; Spagnolo, R. J. Porous Mater., v. 7, p. 183, 2000.

36. Zelaya-Angel, O.; Alvarado-Gil, J.J.; Lozada-Morales, R.; Vargas, H.; Ferreira da Silva, A. Appl. Phys. Lett., v. 64, p. 291, 1994.

37. Ferreira da Silva, A.; Veissid, N.; An, C.Y.; Pepe, I.; Oliveira, N. Barros de; Silva, A.V. Batista da. Appl. Phys. Lett., v. 69, p. 1930, 1996.

38. Silva, T.S.; Alves, A.S.; Pepe, I.; Tsuzuki, H.; Nakamura, O.; d'Aguiar Neto, M.M.F.; Ferreira da Silva, A.; Veissid, N.; An, C.Y.J. Appl. Phys., v. 83, p. 6193, 1998. 